\title{
Cross-Cultural Influences on HRM Practices in an African Context: Global Entrepreneurs in Senegal
}

\author{
Mohammad Reza Faraj Tabrizi ${ }^{1}$, Ali Shabanesfahani ${ }^{2}$, Malahat Pouran Safar $^{3}$ \\ ${ }^{I}$ International Business School (IBS), Universiti Teknologi Malaysia \\ ${ }^{2}$ Perdana School of Science, Technology and Innovation Policy, Universiti Teknologi Malaysia \\ ${ }^{3}$ Advance Informatics School (AIS), Universiti Teknologi Malaysia
}

\begin{abstract}
This study is an attempt to illustrate the cross-cultural influences on HRM practices in an African context. Based on the managerial background of the authors, they found the global HRM as avery sensitive and important area of management studies. International human resources have different cultures, and multicultural environments are usually associated with several concerns, misunderstandings and conflicts among the staff.In this study, the authors review several articles about cross-cultural effects on HRM practices across the globe to support the literature review of this manuscript. Furthermore, the authors distribute a set of questionnaire among 25 international SME (Small and medium enterprises). The respondents of the study are selected among owners of restaurants, hotels as well as some import/export companies in Dakar. The results of the questionnaire are analyzed carefully in order toelaborate the opinions of the respondents. In the findings section, the authors summarize most important issues due to the gathered opinions. Finally, the authors provide a summary of the study and the results on conclusion part and recommend some points for further studies in future.
\end{abstract}

\section{Background}

\section{Introduction}

The global business management became one the most interesting areas of trade,especially for international contractors who are capable to export engineering activities as well as for investors and entrepreneurs who are interested to establish a factory in other countries. They may enjoy lower manufacturing overhead or labor costs. Nowadays there are several engineering export companies who are active in the fields of oil and gas, electricityas well aswaterprojects.Due to the profitable nature of the job, the number of service exporters is increasing so fast.Furthermore,the governments provide lots of advantages and incentives for exporters to promote the domestic economy.In addition to governmental supports, the international banksas well as Chambersof Commerce are alsokeyfacilitators to motivate engineering companies to conduct more and more projects across the globe.But in spite of the aforementioned supports and facilities,the global business management could be considered as a veryhard and challenging task. It is a kind of professional activity and several aspects of the managerial knowledge must be consideredin such activities. It is necessary to establish several disciplines to fulfill the objectives of the business in the framework of the assigned budget and time schedule to satisfy the all the stakeholders.Between managerial aspects, the human resource management (HRM) is a very sensitive subject that has an important roleing lobal businesses (EBERLEIN, 2008). It is clear that local people of each country have their own ideas, ethics and religions which some of them are considered as cultures and the others are sub - cultures.The major obstacle of an overseas project communication with new people with unrelated cultural behaviors and different languages.Managing multicultural human resources who come from different beliefs, languages,legends, religions, and social behaviors is a very complicated task.In addition, it is not possible to follow the same procedures and disciplines of HRM in every country because regional cultures are not similar in many cases,sothe effect of human behavior on organization is unforeseen. Because of the importance of global HRM, several researches are conducted, but again there are many areas of concern regarding cross-cultural influences onglobal HRM practices .Due to the potential markets in Africa and several intensives for the global investors, many international companies became interested to establish new businesses in Africa .So, it goes without saying that several investigations must be conducted to understand more about the cross-cultural influences in Africa context. In this study,the authors focus on HRM practices in Senegal .

\section{Problem Statement}

The international companies, who are active in global business management, engineering export as well as manufacturing and production across borders, usually sufferfrom misunderstandings and conflict in the working environment.Consequentlycostmanagement, time management and quality management are affected due to the failure in proper communication .Usually, coordination of globalcontractorsinWestAfrica is not easy 
because the domestic contractorsarecomposed of the local human recourses and human resources are totally different from one nation to another nation.It is very difficult to give a unique prescription for all countries. Some of the human resources respect the time and in opposite ion there are some people who never care about the appointment time.In fact sometimes, the life style may causeparticular social behaviors. As an example,receiving missed calls is a normal practice in many countries. The international investors and entrepreneur in those countries should know that usually the employees will not spend any phone credit to call them and report about the progress of the job , they will leave you a missed call and wait for a call back. Infact ,It became one of the daily practices in several countries. So, if a contractor conducts a construction project in such countries without enough investigation sabout particular habits and practices, the challenges of the project will not be limited to budget overrun, but also several more challenges will cause headaches for the contractor. For instance, site workers or even the site managers will not report very important issues through the mobile phone.

\section{Purpose of the Study}

According to the increasing level of interest to doing business in Africa as a potential market with significant demand for food, beverage, energy and construction as well as other engineering goods and services , the exporters and international entrepreneurs should learn more about proper HRM practices and overcoming cross-cultural challenges in Africa. It is one of the major tasks of the relevant companies and they should be aware of the cross-cultural influences in global HRM (African context) to provide an accurate business plan for their investments or projects in Africa.They should learn how to splash a positive energy in the working environment and motivate the local staff to contribute effectively in business process. The purpose of this study is to explain about cross-cultural issues that may affect HRM practices in Senegal.

\section{Objectives of the Study}

The objectives of this study to explain about the impacts of cultural factors on man power and labors in Senegal and to recommend some practical solution to prevent such influences at the beginning stages of a new businessor to mitigate such negative impacts.

\section{Significance of the Study}

Although cross-cultural influences on HRM practices in an African context is still a broad issue andit is impossible to verify all of the challenges in this limitedacademicresearch,thepaper is an attempt to elaborate about the issue as much as possible, the results of this study canhelpinternationalcompaniesto have a better insight into the cross-cultural issues in western African countries, especially in Senegal.Alsothisstudycan help global companies to focus on cross - cultural knowledge to conducttheir projects or investments in a professional manner.Furthermore,findingscan help the management students to understand more about cross cultural influences on managerial aspects.

\section{Scope of the Study}

The scope of this study is human resource management in Senegal and the relevant cross-cultural influences .To elaborate more about the issue, the authors study several articles, also a set of questionnaire is designed and distributed among international SMEs in Senegal.

\section{Literature Review}

Both of the academic researches and experiential findings confirm that the issue of culture is the most important issue in HRM practices of international projects, and it has several links to the other project management areas of knowledge, because of the importance of understanding and communication with a variety of staff by dissimilar cultures.But cross-cultural management skill is not sufficient for human resource management and it should be associated with the other managerial abilities to be useful in global projects (EBERLEIN, 2008).

In other word, if somebody has enough qualification in cross-cultural management, it is not enough to approve that person as a deserved project manager for overseas project, he or she has to have enough knowledge and qualification in several management areas.

The culture could be categorized in two segregated modules. The first module is a tangible module and includes lifestyles, languages, regulations, procedures, etc.While the other module is invisible.Itincludes standards ,characters, philosophies, opinions and ideas as well as ethics, flavors, approaches, norms , prospects and mythologies(EBERLEIN, 2008).

Since this study is about HRM practices in Senegal and it is related to cross-cultural human resource management ,the authors explain more about the human resources of the specified country .Senegalese have several ethics as illustrated in Figure 1 (Gates \& Appiah, 2010). 


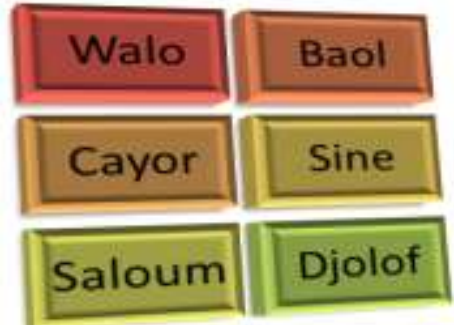

Fig. 1 Tribes in Senegal (Gates \& Appiah, 2010)

The important note is that the above different tribes can generate different human resources for the society, so when an international entrepreneur employs a Baol worker, that specified staff would be different with a Walo or a Djolof worker .

For example, someSenegalesebelievethat Baol people are very good in business, while Saolum people are intelligent but more simple in trading .In such cases, the international entrepreneur has no enough time to read about all of the cultural dimensions of the Senegalese, and it is better for them to hire a local consultant and try to solve several cultural issues.

The majority of Senegalese are from ethnic groups ofWolof, Pular and Serer. The rest groups are Soninke, Diola and Mandink . They have the minimum proportion of the population (Juang \& Morrissette, 2008). The following pie chart depicts the proportion of the population of each group .

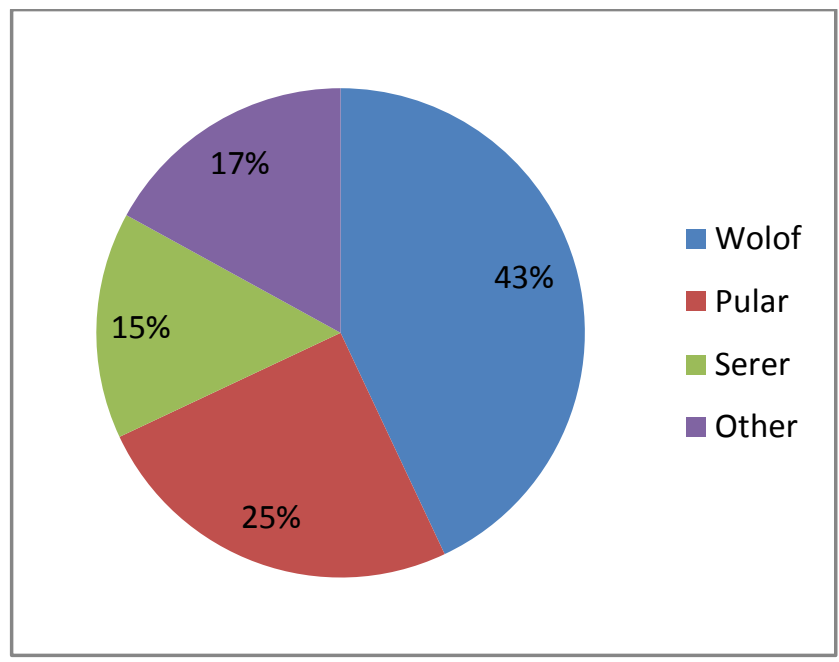

Fig.2 Different Ethics in Senegal

According to the above pie chart, the proportion of Wolofand Pular is very much considerable, so if an international company wants to be successful, it is recommended to focus on learning Wolof and Pular languages.

It is clear that at the beginning stages of the business, it is necessary to hire a local HR manager or a local consultant for recruitment, but learning those two languages can reinforce the foundations of the business. In Senegal, it is also important to know about local habits of people and their normal lifestyle .People are very oriented to music,art and dance,they are very happy by nature. According to AIDARA Mamadou Lamine , a local Senegalese that previously worked with the first author of this study (in an Electrical project for high voltage electrification in Tobene, Touba and Kaolack cities of Senegal),Senegalese like to have peace.

In fact, peace is more important than money for Senegalese. AIDARA Mamadou Lamine argues that even if people are poor they try to be happy and live in harmony with each other. Although the majority of Senegalese is Muslim, they live in a harmony with flowers of other religions. In fact, they live peacefully together. Senegalese respect other cultures, but they also need that the other nations respect them. For the Senegalese the praying time is very important and the foreigner must understand the theological values and significance of Islamic practices in Senegal (AIDARA, 2011) .

There are more thing that any international enterprise has to know before any business action in Senegal, but according to the limitation of this study, there is no time to explain about all of them . Just in order to illustrate the ideas of some international enterprises in Senegal, a set of questionnaire distributed between 25 non-Senegalese SME in Dakar and the results are reflected in this paper. 


\section{Research Methodology}

In this study, the authors collect the primary date by distributing a set of questionnaire between 25 nonSenegalese SME in Dakar.Furthermore an interview is conducted with AIDARA Mamadou Lamine, this gentleman used to work with the first author of the paper in an Electrical project in Senegal several years ago and AIDARA understands the cross-cultural issues very well.The authors discuss about the answers of the respondents to the most important questions and illustrate it by some bar charts in the next section.

\section{Findings And Discussion}

After collecting quantitative data from 25 respondents (international SMEs), data analysis is the important stage to illustrate the ideas of the respondents about the study questions, the results of the data analysis are as followings:

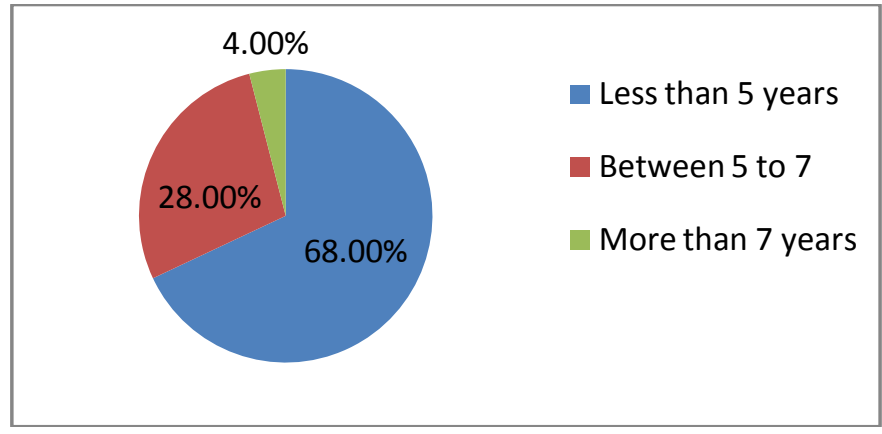

Fig.3 Experience of the respondents

The above pie chart shows that the majority of the respondents are new in doing business in Senegal and only $4 \%$ of them are active in Senegal for more than 7 years.

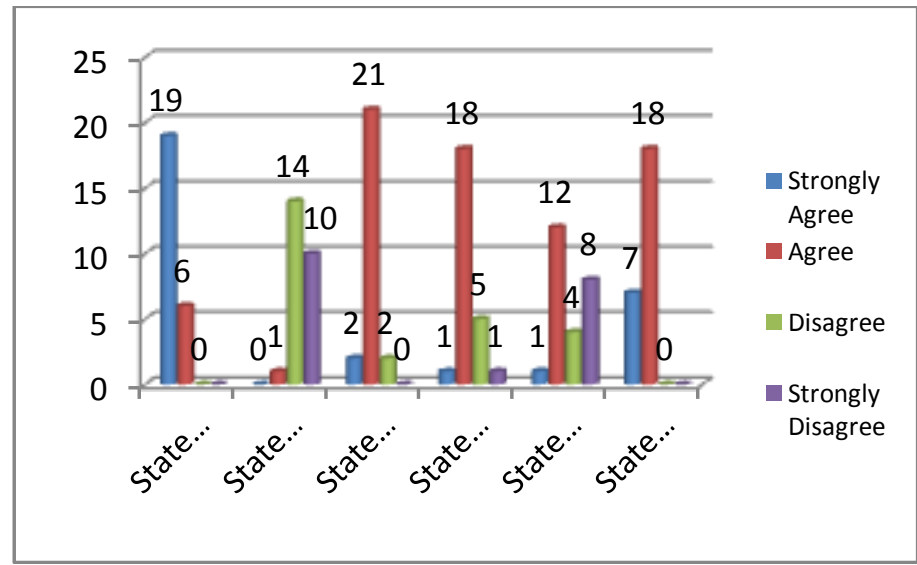

Fig.4 Level of Agreement

Statement $1:$ HRM practices are affected by culture.

The above figure illustrates very well that nobody disagree with this point.

Statement $2:$ HRM is an easy task in Senegal.

The above bar chart shows that only one of the respondents agrees this argument, so the majority of the respondents believes that HRM is not an easy task in Senegal.

Statement 3 : It is necessary to know about different tribes in Senegal.

The above bar chart shows that the majority of the respondents approves this point.

Statement 4 : Senegal Culture is highly affected by religion.

The results show that the big majority of respondents approves this statement.

Statement 5: It is necessary to make pressure on localHR, otherwise they do not conduct their tasks themselves. 
According to the above bar chart, this is a debatable issue among the respondents, almost $50 \%$ of the respondents believe that without pressure, the human resources will not work properly and almost $50 \%$ disagree This means that ideas of enterprises are not same about this issue. It is probably because some of them do not care about human resources.

But, it is also possible that some of enterprises found that Senegalese are not very fast and serious in doing tasks on time, so they believe that more pressure can increase efficiency. According to the interview with AIDARA the authors conclude that Senegalese people will contribute less with higher working pressure and they work better in normal and friendly working conditions(AIDARA , 2011).

Statement $6:$ Local people are trustful in general.

All of the respondents approve it, so in spite of poverty among the Senegalese human resources, they are really honest and trustful and it is one of the valuable advantages of local staff in Senegal.

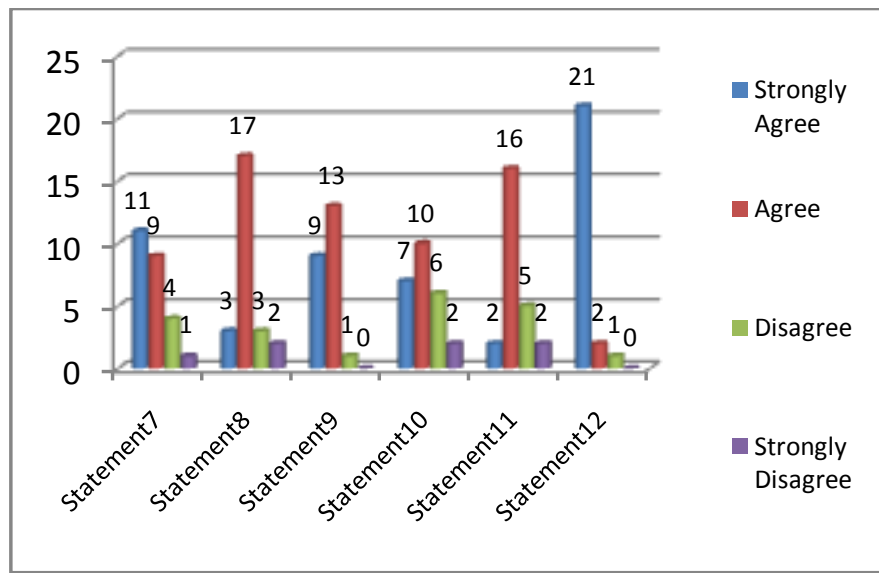

Fig.5 Level of Agreement

Statement 7: Playing traditional music in working environment is effective to increase efficiency.

According to the bar chart, almost $80 \%$ of the respondents confirm this point.

Statement 8 : If the employer eats Senegalese food with hand, the staff like him/ her.

The majority of the respondents agrees with this argument.

Statement 9 :It is important to release Senegalese staffs for Friday praying to increase their satisfaction level.

Only of the respondents disagree with this point, so almost $96 \%$ agreed. The interview with AIDARA shows the same result and he believes that the foreigners should respect local theological beliefs to be more successful in their business. In fact no international company has right to assign any working task during praying time for Senegalese worker (AIDARA, 2011).

Statement 10 : Senegalese people are artist in general.

$100 \%$ of the respondents agree with this argument.

Statement 11 : It is important to hire a local people as head of HRM to communicate better with local staffs.

About $72 \%$ of the respondents agree with this point of view.

Statement 12 : It is important to speak in the Wolof language with the local staffs for better efficiency.

About $96 \%$ of the respondents agree this point, so it is important for international enterprises to learn about Wolof language for doing business in Senegal.

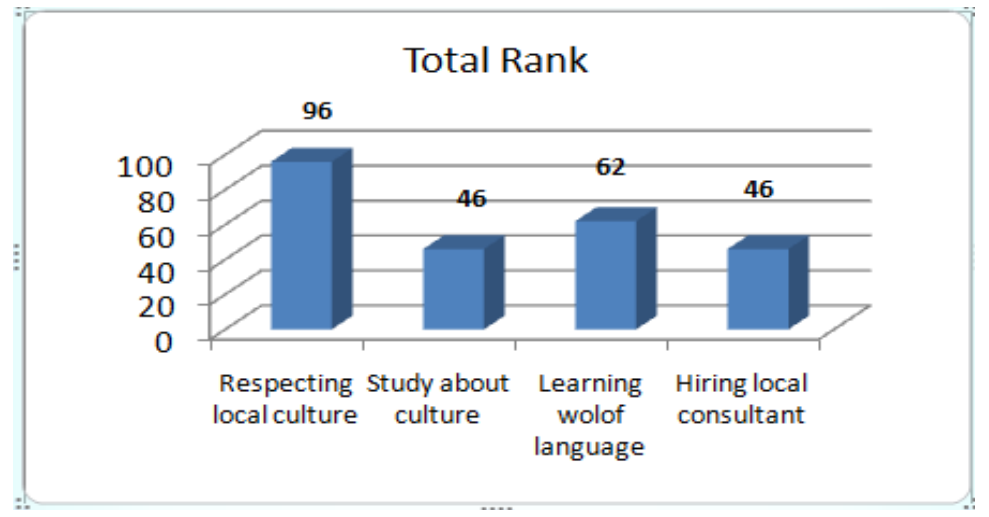

Fig.6 Ranking

www.iosrjournals.org 
According to the above bar chart, the majority of the respondents believes that the most important item in dealing with Senegalese culture, is to respect the local culture, then to learn about local language which is Wolof . Based on the results of the data analysis, studding about culture and hiring a local consultant both equality get the 3 rd rank.

\section{A. Overview of the Study}

\section{CONCLUSION}

This study is an attempt to provide an awareness for international companies and give them some ideas about cross-cultural influences onglobal HRM .The study is specified about HRM practices in Senegal .In order to achieve the objectives of this study, several literatures are reviewed and a set of questionnaire is designed and forwarded to 25 international SME in Senegal as respondents of the study.Furthermore one interview is conducted with Mr. AIDARA. The gentlemean used to work mutually with the first author of this paper in an Electrical project between Iran and Senegal and he is fully aware of multicultural business environment based on his observations.In this study the findings areconcluded based on the primary data and the secondary data provideenoughinsight for the authors to conduct the research properly .

In conclusion ,the authors argue that doing business in abroad without knowledge about cross-cultural issues is so difficult. The authors emphasize on the conducting several surveys about local cultures, habits, values, legends, lifestyle, etc. prior to doing any project overseas . Eventually, anybody must learn to respect the other culture and avoid provocative cultural discussions in any business.

\section{B. Restatement of Objectives}

The objective of this research is to explain about the impacts of cultural factors in dealing with work forces and labors in Senegal. Also recommend some practical solution to mitigate such influences at the beginning stages of any business in that region to manage domestic human resources properly.

\section{Limitations of the Study}

Since, only 25 respondents were selected and only one interview conducted, it is not very accurate to address the results of this study to all of the multicultural HRM practices in Senegal.

\section{RECOMMENDATION}

For future studies, the authors recommend to conduct a similar research, but distribute more than 100 sets of questionnaire to gather a more accurate data to conduct several interviews to achieve qualitative data too.

\section{ACKNOWLEDGMENTS}

First and foremost, thanks GOD for enabling us to conduct this academic research .Furthermore, the authors appreciate all the esteemed respondents of the study especially Mr. AIDARA for his strong support.. The last, but not the least, the authors appreciate their families that support them in this study.

\section{REFERENCES}

[1] AIDARA , L. M., 2011. Human Resource Management and issue of culture in Senegal [Interview] (27 November 2011).

[2] Anon., n.d. Peace Corps Cross-Cultural Workbook. Washington DC: U.S. Government Printing Office.

[3] EBERLEIN, M., 2008. CULTURE AS A CRITICAL SUCCESS FACTOR FOR PROJECT MANAGEMENT. Journal of Information Technology Management, Volume XIX, p. 35.

[4] Eberlein, M., 2008. Culture as a critical success factor for successful global project management in Multi-National IT service projects. Journal of Information Technology Management, XIX(3), pp. 27-42.

[5] Gates, H. \& Appiah, K. eds., 2010,May 27. Encyclopedia of Africa. New York: Oxford University Press.

[6] Gates, H. L. \& Appiah, K. A., 2010. Encyclopedia of Africa. New York: Oxford University Press.

[7] Greenhalgh, L., 2001. Ford Motor Company's CEO Jac Nasser on transformational change,E-Business, and environmental responsibility. Academy of Management Executive, Volume 14, pp. 46-51.

[8] Juang, R. \& Morrissette, N. eds., 2008. Africa and the Americas Culture, Politics, and History. Santa Barbara: ABC-CLIO. 